\title{
Synthesis and characterization of alkali-activated loess and its application as protective coating
}

\author{
Jean-Baptiste Mawulé Dassekpo ${ }^{\mathrm{a}}$, Weipeng Fenga ${ }^{\mathrm{a}}$, Yanru Li ${ }^{\mathrm{a}}$, Lixin Miao ${ }^{\mathrm{b}}$, \\ Zhijun Dong ${ }^{\mathrm{a}, *}$, Jianqiao Ye $\mathrm{e}^{\mathrm{c} *}$ \\ ${ }^{a}$ Institute of Technology for Marine Civil Engineering, Shenzhen Institute of Information \\ Technology, 518172, China \\ ${ }^{b}$ Research Center for Modern Logistics, Tsinghua Shenzhen International \\ Graduate School, 518055, China \\ ${ }^{c}$ Department of Engineering, Lancaster University, Lancaster, LA1 4YR, UK \\ *Corresponding author emails: dongzj@sziit.edu.cn; j.ye2@lancasyer.ac.uk
}

\begin{abstract}
Environmental friendly and sustainable repair materials with reduced carbon emission have been in high demand worldwide. Frequent deterioration of cement concrete structures is unpreventable and requires appropriate repair materials. Aside from the cementitious, polymeric or resinous materials used to remedy this problem, geopolymeric mortars are reported to be friendly and more sustainable, considering the lower energy required for its production and its intrinsic properties. When selecting geopolymer produced from aluminosilicate waste as repair materials, a measured dissolution in an adequate alkaline solution is required for geopolymerization. Accordingly, this paper examines the synthesis and properties of alkaliactivated loess, followed by its effective application as concrete protective coating. The geopolymer mortars (GPMs) were made from loess and ground granulated blast slag (GGBS), and activated with either sodium hydroxide or a combination of sodium hydroxide and sodium silicate solutions. Experimental results showed that, both alkali activators have major influences on the apparent viscosity, roughness, compressibility and microstructural properties of loess GPMs. Results from nanoindentation also reveal good adhesion, higher bulk indent modulus and hardness of the applied mortar, a fact that makes loess geopolymer a great potential repair material to be used as barrier coating for cement concrete substrates.
\end{abstract}

Keywords: Loess, Slag, Alkali-activator, Viscosity, Roughness, Nanoindentation, Coating. 


\section{Introduction}

Perhaps the notable challenge of reducing climate disruption and environmental impacts comes from the manufacturing of cement, which represents a principal construction material. Globally, around 4 billion metric tons of Portland cement are manufactured every year. Despite the innovative progress made in the manufacturing process, the productivity of cement remains responsible for around $6 \%$ of all man-made $\mathrm{CO}_{2}$ emissions [1]. Accordingly, an environmentally friendly alternative material is desirable from both an economic and environmental point of view. Geopolymer is one of the alternative material for application in the building and construction industry. In fact, to mitigate the adverse effect of OPC on the environment, several geopolymers derived from natural, industrial or by-products waste have been developed with satisfactory results [2-14].

As an integrated process for geopolymer synthesis, geopolymerization involves the reaction between two parts of raw materials, namely: aluminosilicates and alkali activators. During geopolymer synthesis, alumino-silicate source materials are dissolved into alkali liquid forming free tetrahedral units $\left(\mathrm{SiO}_{4}\right.$ and $\left.\mathrm{AlO}_{4}\right)$. The free $\mathrm{SiO}_{4}$ and $\mathrm{AlO}_{4}$ tetrahedrons are then linked alternatively, where the charge-balancing cations are provided by alkali metal cations to yield polymeric precursors $\left(-\mathrm{SiO}_{4}-\mathrm{AlO}_{4}\right.$, or $-\mathrm{SiO}_{4}-\mathrm{AlO}_{4}-\mathrm{SiO}_{4}-$, or $\left.-\mathrm{SiO}_{4}-\mathrm{AlO}_{4}-\mathrm{SiO}_{4}-\mathrm{SiO}_{4}-\right)$ by sharing all oxygen atoms between the two tetrahedral units thereby forming monolithic geopolymer products $[15,16]$. The entirety and success of the process are sensitive to and have a close relationship with the curing temperature, the activating synthesis solution $[17,18]$ and the sequential addition of the synthesis parameters [19]. The hardening of geopolymer is obtainable at ambient temperature or moderate elevated temperature, depending on the degree of reactivity of the source materials.

Alkali solutions, such as sodium hydroxide $(\mathrm{NaOH})$ and sodium silicate $\left(\mathrm{Na}_{2} \mathrm{SiO}_{3}\right)$ solution that are commonly called waterglass, are the most frequently used reactant during the synthesis of geopolymer. The activation process is influenced by a range of factors beyond the alkali molarity [20], such as aluminosilicate fineness, type of activator and liquid to binder ratio. The main components responsible for the hydration and strength formation of geopolymer is the modulus of the waterglass. i.e. the molecular ratio of $\mathrm{SiO}_{2}: \mathrm{Na}_{2} \mathrm{O}$. So far, several studies have shown that the concentration of the alkali liquid can significantly impact the mechanical characteristics of a geopolymer [21-24]. For instance, according to Heah et al. [25], the average $\mathrm{Na}_{2} \mathrm{O}$ content in a 
geopolymer system can increase aluminosilicate source solubility whereas its excessiveness weakens the formed structure. Furthermore, Panias et al. [26] claimed that the volume of $\mathrm{Na}_{2} \mathrm{SiO}_{3}$ solution in the geopolymerization process had significant influences on the compressive strength because it determined the concentration of the soluble silicate in the geopolymeric system. In their influential work and findings, Pacheco-Torgal et al. [27] established that by activating metakaolin with sodium hydroxide, the flexural and compressive strength increased with the increase of sodium hydroxide.

In general, geopolymer is reported to be friendly and more sustainable than OPC when considering the low energy required for its production in addition to its low $\mathrm{CO}_{2}$ emissions [2830], a fact that makes geopolymer a promising material for the construction industry. Geopolymer has over the years been increasingly used, as a coating material, to protect marine concrete structures and transportation infrastructures [31]. When selecting geopolymer as a repair material, it is important to consider the bond strength between the geopolymer and the substrate concrete [32-34], as the bond plays a decisive role in the effectiveness of the repairing. Concrete repair work often employs commercial repair materials that have adequate mechanical and bond strength properties but they are normally expensive and may not be environmentally friendly. Cheaper versions of the materials have poor mechanical and bond properties. Thereby causing researchers to examine the utility and application of geopolymer as a repair material by using different waste or by-products [35-38].

This research studies the properties and applications of loess geopolymer along with added ground granulated blast slag (GGBS). Loess is a natural material dating back to ancient periods when it was used for the manufacture of pottery. It is yellow in color, porous, clastic and crumbly deposit largely composed of silt, sand and clay particles. Generally, over 50\% (in weight) of loess are silt particles of around $0.005-0.05 \mathrm{~mm}$. Silt particles larger than $0.25 \mathrm{~mm}$ or smaller than 0.005 $\mathrm{mm}$ are few [39]. Around the world, loess deposits are largely found [40-43] in the forest and desert areas of the southern and northern hemispheres. This represents about $10 \%$ of the earth's surface [39]. In China, loess deposits covers about $640,000 \mathrm{~km}^{2}$, which is about $6.7 \%$ of the country's total area [44]. GGBS, on the other hand, is a glassy and granular material primarily made up of $\mathrm{SiO}_{2}, \mathrm{CaO}, \mathrm{Al}_{2} \mathrm{O}_{3}$ and $\mathrm{MgO}$. Its formation occurs when molten blast furnace (BF) slag, a by-product in iron making, is cooled swiftly using water, and then grounded to improve its reactivity [16]. The main reactive product observed in the alkali activation of slag, is a hydrated 
calcium-silicate $(\mathrm{C}-\mathrm{S}-\mathrm{H})$ gel with low $\mathrm{C} / \mathrm{S}$ ratio $[45,46]$, known to enhance the setting and strength properties of geopolymer $[45,46]$.

Some research has been carried out on loess geopolymers [3, 47-50]. Although loess can be used in the production of geopolymer, its activation of the geopolymerization process presents some difficulties. Accordingly, this study depends on the utilization of two key wastes materials: loess and ground granulated blast slag (GGBS) in the production of GPMs. Synergistically, the effect of alkali solutions on loess is addressed through the use of only $\mathrm{NaOH}$ and the combination of $\mathrm{NaOH}+\mathrm{Na}_{2} \mathrm{SiO}_{3}$ with addition of GGBS (10, 20 and 30\%). In order to study the possible utilities, the developed geopolymer loess is applied as coating for concrete substrates in normal temperature conditions and the results are analyzed. Viscosity measurements were performed in order to study the flowability of the fresh geopolymer loess (GPMs). Steps are also undertaken to evaluate the compressibility of the hardened GPMs with different alkali activators and the increasing amount of GGBS, in terms of its microstructure as well as its nanomechanical properties.

\section{Experimental program}

\subsection{Raw materials}

Loess, acquired from Shaanxi Province in China, and ground granulated blast slag (GGBS), are the primal matter used in this paper. Like aforementioned, the use of loess is preferable because of its ready availability, low costs and its richness in aluminosilicate species. Both raw materials were submitted for X-Ray Fluorescence (XRF) analysis by the aid of Thermo Fisher ARL Perform'X. The results, as shown in Table 1, reveals that loess is mainly composed of $60.07 \%$ $\mathrm{SiO}_{2}$, and $25.09 \% \mathrm{Al}_{2} \mathrm{O}_{3}$. Other species such as $\mathrm{Fe}_{2} \mathrm{O}_{3}, \mathrm{CaO}, \mathrm{MgO}$ and $\mathrm{K}_{2} \mathrm{O}$ were also presented with low percentages. Similarly, the analysis on GGBS presents $19.87 \% \mathrm{SiO}_{2}, 5.92 \% \mathrm{Al}_{2} \mathrm{O}_{3}, 4.14 \%$ $\mathrm{SO}_{3}, 3.63 \% \mathrm{Fe}_{2} \mathrm{O}_{3}$ and $62.75 \% \mathrm{CaO}$. It can be seen that loess is dominated by $\mathrm{SiO}_{2}$ and $\mathrm{Al}_{2} \mathrm{O}_{3}$ oxides; while GGBS is mainly composed of $\mathrm{SiO}_{2}$ and $\mathrm{CaO}$ oxides.

Microstructural characterization and EDX oxides mapping on the raw materials was also performed, and the visuals of both powders are presented in Fig. 1. From the SEM images, it can be seen that, loess is composed of spherical particles with irregular surfaces whereas GGBS presented in abundance regular sheets and round microparticles. Moreover, the elemental distribution of $\mathrm{Si}, \mathrm{Al}$ and $\mathrm{Ca}$ through each powder is also presented. In general, it can be seen that $\mathrm{Si}$, and $\mathrm{Al}$ oxides are evenly distributed on the surface of loess and GGBS, and $\mathrm{Ca}$ oxide is almost 
absent in loess powder (Fig. 1a). Contrariwise, the distribution of Ca is very remarkable in GGBS powder (Fig. 1b). This is in accordance with the results obtained from the X-Ray Fluorescence analysis, which indicated less percentage of $\mathrm{CaO}(1.58 \%)$ for loess and high volume for GGBS $(62.75 \% \mathrm{CaO})$.

\subsection{Alkaline solutions}

Alkaline solutions play a critical role in the synthesis of geopolymer. Generally, for geopolymer activation, an alkaline solution composed of sodium hydroxide/potassium hydroxide and sodium silicate/potassium silicate is frequently used. In particular, this study used two types of alkali solutions. The first in Mix 1 is composed of $\mathrm{NaOH}$ in pellets form of $99 \%$ purity, dissolved in water with concentration of $8 \mathrm{M}$. It is pertinent to note that $\mathrm{NaOH}$ solution with a concentration of $8 \mathrm{M}$ comprises of $8 \times 40=320$ grams of $\mathrm{NaOH}$ per litre of the solution, where 40 represents the molecular weight of $\mathrm{NaOH}$. Upon measuring $\mathrm{NaOH}$ solids, 262 grams per $\mathrm{kg}$ of $\mathrm{NaOH}$ solution of $8 \mathrm{M}$ concentration was made and the sodium hydroxide solution after dissolution was kept at rest for 3 hours before being used. The second alkali solution (Mix 2) is composed of $\mathrm{NaOH}$ of the same molarity as the first one and an added sodium silicate $\left(\mathrm{Na}_{2} \mathrm{SiO}_{3}\right)$. The resultant solution was prepared by mixing the $\mathrm{NaOH}$ and $\mathrm{Na}_{2} \mathrm{SiO}_{3}$ solutions.

\subsection{Mixing, casting and curing of GPM}

This study examines the outcome of $\mathrm{NaOH}$ and $\mathrm{Na}_{2} \mathrm{SiO}_{3}$ on the characteristics of loess GPM using two different mixtures with the same volume of loess and the same molarity of $\mathrm{NaOH}$. Loess calibrated at $90 \%, 80 \%, 70 \%$ and $100 \%$ were respectively mixed with $0,10,20$ and $30 \%$ GGBS to prepare GPMs cured at ambient temperature after heating for $24 \mathrm{~h}$. The details of the mix proportions follow the research of Dassekpo et al. [51].

Initially, for about 3 minutes, loess and GGBS were dry mixed in a rotating pan mixer and then sodium hydroxide and or sodium silicate was added to the mixer. After 6 minutes of wet mixing, sand was added and mixed for another 3 minutes. The fresh GPM was then cast in $70 \mathrm{x}$ 70 x $70 \mathrm{~mm}$ plastic molds and compacted on a vibrating flat surface for 2-3 minutes to remove entrapped air in the mixture. For each test variable, three cubes were prepared. Sealed samples were then rested at ambient temperature for 4 hours. After the resting period, the samples were removed from the molds and left for heat curing at $70^{\circ} \mathrm{C}$ and $50 \% \mathrm{RH}$ for $24 \mathrm{~h}$. Finally, the samples were dried at ambient temperature until the testing time. 


\section{Testing details}

\subsection{Viscosity measurements}

The viscous behavior of cement paste, mortar or concrete in many cases can be accurately described by the Bingham model (Eq. 1); in which $\tau$ represents the shear stress, $\tau_{0}$ yield stress, $\eta_{p l}$ plastic viscosity and $\dot{\gamma}$ the shear rate, contrary to Newtonian fluids, where the shear stress and rate are commensurate, the minimum stress - the yield stress - is necessary for flow to occur. The viscosity properties of GPM with $70 \%$ loess and $30 \%$ GGBS in both mixtures were measured at ambient temperature immediately, after the mixtures were evenly mixed using RM100 Touch viscometer (Lamy Rheology Instruments).

$$
\tau=\tau_{0}+\eta_{\mathrm{pl}} \cdot \dot{\gamma}
$$

\subsection{Compressive strengths measurement}

The classification of a cementitious material is primarily determined by its compressive strength. Accordingly, many researchers employ compressive strength results as a tool to assess the success of geopolymer synthesis and cementitious binders [52-54]. The compressive strength of the hardened GPM in this study were tested after 7 and 28 days in accordance with ASTM C39/C39M-16a [55]. The values obtained from the tests were computed and analyzed.

\subsection{Applied thickness and surfaces roughness}

The primary role of coatings is to preserve or restore concrete structures following welldefined properties and standards. However, there are some particular technical issues with geopolymer coatings on cement substrates, especially in regards to temperature, that intervenes in the overall geopolymerization process. This study focuses on applying the developed loess GPMs onto cement concrete substrates at ambient temperature.

A year-old broken concrete was collected and both GPMs were applied separately to the concrete fractured surfaces. A thickness of around $t=3 \mathrm{~mm}$ of both GPM mixtures were chosen following the requirements as outlined in BS EN 1504-3:2005 standard [56] for structural and nonstructural repairs. The coated samples were cured at ambient curing for 24 hours and small fractures were collected and submitted for roughness test using Contour GT-X, Optical Profiler (Bruker Instruments). 


\subsection{EDX and SEM analysis}

Microstructural characterization and chemical elements of the tested loess GPMs were examined using Zeiss Gemini 300 X-MAX ${ }^{\mathrm{N}}$, Microanalysis Oxford Instruments. For the EDX test, the morphology of the white crystals presented in the materials were analyzed. Samples of about 3-6 mm were taken from the middle section of the GPM samples for the SEM tests. The samples were dried by infrared light for 6 minutes and then gold coated using a blazer sputtering coater.

\subsection{Mercury intrusion porosimetry (MIP) test}

In this study, MIP, Micromeritics Instrument Corporation AutoPore IV 9500 Version 2.00 was used to evaluate the pore structure of GPM-3 for both Mixtures at 28 days of curing. For this test, the GPM samples were placed into a chamber and then submerged in pressurized mercury of up to 61,000 psia. Mercury surface tension, which ranges from 0.473 to $0.485 \mathrm{~N} / \mathrm{m}$, can be explained as the contractive proclivity of the liquid surface to withstand an external force. The mercury surface tension was assumed to be $0.485 \mathrm{~N} / \mathrm{m}$. The extrusion contact angle was taken as $130^{\circ}$, as recommended by Liu and Winslow [57] in order to eliminate the hysteresis of the curve caused by the in-bottle effect during intrusion and extrusion of mercury. The cumulative intrusion as well as the incremental intrusion against pore size diameters of the loess GPM were obtained and analyzed.

\subsection{Statistic nanoindentation test}

The nanoindentation test was performed using Hystron T1950 Triboindentor (Bruker Corp). A tip, with known geometry and mechanical properties, was used to press down on the surface of a sample, which created an indent. A Berkovich tip made of diamond was used and a representative region across the boundary between the geopolymer mortar, and concrete substrate was selected for each sample. A grid of $30 \times 10=300$ indents in each region was made with a spacing of neighboring indents measuring $10 \mu \mathrm{m}$ to ensure the independence of the indents. For each indent, a trapezoid load function was applied up to $5000 \mu \mathrm{N}$, with a linear loading time of $10 \mathrm{~s}$, a holding time of $5 \mathrm{~s}$ and a linear unloading time of $10 \mathrm{~s}$.

Both samples, after 24 hours ambient curing, were placed into a $3 \mathrm{~cm}$ diameter rubber mold with the coated side face down. The samples were embedded in epoxy resin and then grounded for 4 hours following the grinding procedure of Miller et al [58] until an adequate roughness of the 
sample surface was achieved. Under a microscope, the grinding condition was continually checked. Afterward, all the grounded samples were immersed into an ultrasonic bath and washed with ethanol to remove dust and diamond particles. Before the nanoindentation test, samples were kept in a vacuum desiccator to reduce and prevent further hydration and possible carbonation. Fig. 2 shows details of the concrete substrate, the GPM and the indented areas.

\section{Results and discussions}

\subsection{Geopolymerization reactions}

The geopolymer mechanism, as widely known, relies on natural, industrial or by-product materials rich in amorphous-form $\mathrm{Si}$ and $\mathrm{Al}$. The mechanism process as illustrated in Fig. 3 is very complex as it involves multiphase reactions such as dissolution in alkaline solution of the $\mathrm{Si}$ and Al elements, polymerization of the dissolved minerals, precipitation of the formed hydration products and the hardening of the geopolymer matrix [59]. When the binder contains high calcium content, the hydrates tend to form in conjunction with geopolymeric gels. In this paper, due to the addition of GGBS in the mixture, the $\mathrm{CaO}$ component is introduced into the geopolymer system, which transforms the system into a $\mathrm{SiO}_{2}-\mathrm{Al}_{2} \mathrm{O}_{3}-\mathrm{CaO}-\mathrm{Na}_{2} \mathrm{O}-\mathrm{H}_{2} \mathrm{O}$ five-element system. The overall reactions can be expressed as follows:

$$
\begin{aligned}
& \mathrm{SiO}_{2}+\mathrm{Al}_{2} \mathrm{O}_{3} \stackrel{\mathrm{Na}_{2} \mathrm{O}+\mathrm{H}_{2} \mathrm{O}}{\longrightarrow} \mathrm{N}-\mathrm{A}-\mathrm{S}-\mathrm{H} \\
& \mathrm{CaO}+\mathrm{SiO}_{2} \stackrel{\mathrm{Na}_{2} \mathrm{O}+\mathrm{H}_{2} \mathrm{O}}{\longrightarrow} \mathrm{C}-\mathrm{S}-\mathrm{H}
\end{aligned}
$$

The above two reactions show that, the source materials containing a large amount of $\mathrm{Al}_{2} \mathrm{O}_{3}$ and $\mathrm{SiO}_{2}$ can react to form N-A-S-H geopolymer gel under alkaline conditions; and the addition of materials containing $\mathrm{CaO}$ components, such as slag can occur during the $\mathrm{Si}-\mathrm{Al}$ polymerization reaction and $\mathrm{Ca}-\mathrm{Si}$ hydration reaction, and generate $\mathrm{CSH}$ hydrated calcium silicate gel. The $\mathrm{Ca}-\mathrm{Si}$ hydration reaction of $\mathrm{CaO}$ and $\mathrm{SiO}_{2}$ components is basically the same as the hydration reaction of ordinary portland cement. For the dissolution of the raw material rich in $\mathrm{Al}_{2} \mathrm{O}_{3}$ and $\mathrm{SiO}_{2}$, the $\mathrm{Al}-\mathrm{O}$ and the $\mathrm{Si}-\mathrm{O}$ bond are broken under the action of the alkali activator, generating $\mathrm{Si}^{4+}$ and $\mathrm{Al}^{3+}$ ions which are combined with water molecules. The $\mathrm{Si}^{4+}$ and $\mathrm{Al}^{3+}$ ions are the central ions, and the water molecules are the ligands. They share a pair of electrons in the oxygen atom orbitals of the water molecules to form coordination bonds to generate hydrated silicon ions and hydrate. The reaction of an aluminum and silicon rich system is represented by the following. 


$$
\mathrm{SiO}_{2} \stackrel{\mathrm{Na}_{2} \mathrm{O}, \mathrm{H}_{2} \mathrm{O}}{\longrightarrow}\left[\mathrm{Si}\left(\mathrm{H}_{2} \mathrm{O}\right)_{4}\right]^{4+}
$$

$$
\mathrm{Al}_{2} \mathrm{O}_{3} \stackrel{\mathrm{Na}_{2} \mathrm{O}, \mathrm{H}_{2} \mathrm{O}}{\longrightarrow}\left[\mathrm{Al}\left(\mathrm{H}_{2} \mathrm{O}\right)_{4}\right]^{3+}
$$

\subsection{Synthesis behaviors of loess GPM}

\subsubsection{Viscosity analysis}

The curves related to the viscosity and shear stress of the GPMs are presented in Fig. 4. In general, it can be seen that the measured viscosity is relative to the shear stress and rate of the fresh GPMs; and the apparent viscosity increases depending on whether the mixture contains sodium silicate solution. In Mix 1, in which only sodium hydroxide was used (Fig. 4a), the apparent viscosity was found to be 926 Pa.s at 6 s and revolves around 600 Pa.s after 120 s mixing. Similary, Mix 2 activated with a combination of sodium hydroxide and sodium silicate (Fig. 4c) presented an apparent viscosity ranging from 1471-1149 Pa.s at 6 and $110 \mathrm{~s}$, respectively. It is important to emphasize that, in both mixtures, the trend curves remain linear from 20-105 s and 20-100 s, respectively for Mix 1 and Mix 2. This could be attributed to the stable fluidity of the mixtures under the rotative action of the viscometer's probe.

The results of the shear stress that causes flow are displayed in Fig. 4b and Fig. 4d. In Mix 1 (Fig. 4b), two peak stress values of 922.18 and $977.26 \mathrm{~Pa}$ were observed, respectively at $10 \mathrm{~s}^{-1}$ and $90 \mathrm{~s}^{-1}$ shear rate. Likewise, the peaks stress in Mix 2 are found at the same shear rate of $10 \mathrm{~s}^{-1}$ and $90 \mathrm{~s}^{-1}$ with respective values of up to 2286.83 and $4491.66 \mathrm{~Pa}$. It can also be seen that, in the case of an apparent viscosity, the mixture with combined $\mathrm{NaOH}$ and $\mathrm{Na}_{2} \mathrm{SiO}_{3}$, presented high values of stress. By comparing both mixtures, it can be seen that Mix 2 is more viscous than Mix 1 , and the high degree of viscosity is mainly due to the addition of sodium silicate. From both results, it can be concluded that, sodium silicate is the main factor affecting fluidity enhancement of loess GPMs and the shear stress is proportional to the apparent viscosity.

\subsubsection{Compressive strength}

The graphical representation of compressive strength against the GGBS ratio of the examined GPMs after being cured for 7 and 28 days, respectively, with different alkali activators, are shown in Fig. 5(a-b). The results show that the strengths of the GPM are relatively dependent on the alkali-activators. The strength of the mix, activated with only $\mathrm{NaOH}$ (Fig. 5a), represents the lowest values in the range of 2.25-9.07 $\mathrm{MPa}$ and 3.99-10.63 $\mathrm{MPa}$ at 7 and 28 days of curing, 
respectively. The samples activated with $\mathrm{NaOH}+\mathrm{Na}_{2} \mathrm{SiO}_{3}$ present higher compression strength, which is in the range of 10.31-12.75 MPa for 7 days curing, and 17.25-27.26 MPa at 28 days (Fig. $5 b)$. The loess without added GGBS gains a strength of up to $3.99 \mathrm{MPa}$ for the mixture activated with only $\mathrm{NaOH}$ and approximately $17.25 \mathrm{MPa}$ when activated in a mixture of $\mathrm{NaOH}+\mathrm{Na}_{2} \mathrm{SiO}_{3}$ at 28 days curing time. Evidently, the strength of the GPM increases with the increase of GGBS content in both cases.

\section{- Effect of $\mathrm{NaOH}$ and $\mathrm{Na}_{2} \mathrm{SiO}_{3}$ on loess}

In the synthesis of geopolymer, the type of alkali activators and the molarities of $\mathrm{NaOH}$ and $\mathrm{Na}_{2} \mathrm{SiO}_{3}$ significantly affect the mechanical and microstructural properties of the material. $\mathrm{NaOH}$ concentration in the aqueous phase of the geopolymeric system plays a principal role in the dissolution of $\mathrm{Si}^{4+}$ and $\mathrm{Al}^{3+}$ ions from the source materials as well as bonding of the solid particles in the final structure [24, 60]. The compressive strength of the loess GPM with the two alkali solutions is shown in Fig. 5. The test results demonstrate the influence of $\mathrm{NaOH}$ and $\mathrm{Na}_{2} \mathrm{SiO}_{3}$ on the material performance. In general, the compressive strength of a geopolymer gained from activating only by sodium hydroxide, is low [61, 62], and the compressive strength of the GPM is greater when a mixture of $\mathrm{NaOH}$ and $\mathrm{Na}_{2} \mathrm{SiO}_{3}$ is used as an activating solution. Accordingly, the use of the combination of $\mathrm{NaOH}$ and $\mathrm{Na}_{2} \mathrm{SiO}_{3}$ showed significant improvement in the compressive strengths both after 7 and 28 days of curing. It can therefore be concluded that the addition of $\mathrm{Na}_{2} \mathrm{SiO}_{3}$ in the mixture can enhance the synthesis of geopolymer and improve its compressive strength.

\section{- Effect of GGBS addition on loess performance}

It is obvious that the addition of GGBS in the mixtures greatly influenced the material's performance. The compressive strength in both series increases gradually as the proportion of GGBS increases. Importantly, it is worth noting that the loess mixture can reach a compressive strength of up to $2.25 \mathrm{MPa}$ and $3.99 \mathrm{MPa}$, respectively at 7 and 28 days curing, respectively, when activated with only $\mathrm{NaOH}$, whereas when activated with $\mathrm{NaOH}$ and $\mathrm{Na}_{2} \mathrm{SiO}_{3}$ the strength increases up to $10.31 \mathrm{MPa}$ at 7 days and 17.25 $\mathrm{MPa}$ at 28 days curing. The improvement in compressive strength confirms the possible synthesis of loess mixed with $\mathrm{NaOH}$ and $\mathrm{Na}_{2} \mathrm{SiO}_{3}$ for its use as a geopolymer precursor. For the Mix 1 (activated only with $\mathrm{NaOH}$ ), the average strengths of loess with addition of 10, 20 and 30\% of GGBS are 3.53, 4.29 and 9.07 MPa respectively at 7 days 
curing and 4.71, 4.71 and 10.63 MPa at 28 days curing. Similarly, the ratio of $10 \% 20 \%$ and $30 \%$ GGBS in Mix 2 (activated with $\mathrm{NaOH}+\mathrm{Na}_{2} \mathrm{SiO}_{3}$ ) can reach a compressive strengths of up to 11.09 $\mathrm{MPa}, 11.98 \mathrm{MPa}$ and $12.75 \mathrm{MPa}$, respectively, at 7 days curing while an enhanced compressive strengths of 25.75 MPa, 27.26 MPa and 27.26 MPa were obtained at 28 days curing. It can also be seen from the results that, the compressive strengths of the GPM with 10 and $20 \%$ GGBS in Mix 1 are the same, as the Mix 2 activated with 20 and 30\% GGBS.

\subsection{Microstructural characterization}

\subsubsection{Coating surfaces roughness}

The coating surfaces roughness were determined by the root mean square deviation from the mean plane surface and the results are presented in Fig. 6. It can be observed that the coating in Mix 1 presents a roughness $\mathrm{Ra}=10.81 \mu \mathrm{m}$, whereas Mix 2 shows $10.33 \mu \mathrm{m}$. From the result, it can be seen that the coating produced from Mix 1 (Fig. 6a) is very rough and has surface cracks. This can be explained by the absence of sodium silicate in the mixture dissolution which affects the proper bonding of the solid particles. On the other hand, the Mixture in Fig. 6c presents a roughness $\mathrm{Ra}=10.33 \mu \mathrm{m}$ with less rough appearance. It can also be seen that, no cracks were presented in the surface of the coating prepared with Mix 2. Moreover, it can be visibly noticed in both profiles a surface differentiation (Fig. 6b-d). The profile in Mix 1 (Fig. 6b) presents an unbalanced surface, whereas in Mix 2 (Fig. 6d) smooth and more or less polished surface was observed. This is proof of a full dissolution of the loess particles under combined $\mathrm{NaOH}$ and $\mathrm{Na}_{2} \mathrm{SiO}_{3}$ solution, which had significant consequences on the coating roughness and surface modification.

\subsubsection{Leaching during curing}

For the GPM samples activated with $\mathrm{NaOH}$, it was found that white needle shaped crystals appeared and grew after 72 hours of curing (Fig. 7). After 7 days, all the surfaces exposed to the air were covered with white crystals and the surface layer started peeling off and crumbling. The white crystals were attributed to the excess sodium, which could not be efficiently retained and incorporated in the matrix, thus caused leaching. For the samples with $\mathrm{NaOH}+\mathrm{Na}_{2} \mathrm{SiO}_{3}$, however, it was seen that they were not covered with crystals. Perhaps this is due to the fact that the reaction rate is slower at lower temperatures thus excess sodium ions, which were not efficiently used, did 
not leach to the surface via pore water and thereby react with the $\mathrm{CO}_{2}$ from the air. The white crystals were collected from the samples for further investigation.

\subsubsection{EDX crystalline phase of the leached white crystal}

The EDX microanalysis was used to check the morphology of the white crystals and the results are presented in Fig. 8. The EDX analysis reveals that the predominant crystalline phase of the white crystal is the alkaline salt with high composition of oxygen (O), carbon (C), silicon ( $\mathrm{Si}$ ), sodium $(\mathrm{Na})$, aluminium $(\mathrm{Al})$ and calcium $(\mathrm{Ca})$. Oxygen elements represent $58.1 \%$. 60.4\% and $54.9 \%$ at spectrum 1, 2 and 3, respectively. Carbon elements display 13.9\%, 12.4\% and $14.7 \%$ at spectrum 1, 2 and 3, respectively. Silicon elements, on the other hand, at 1, 2 and 3 spectrum show 8.7, 13.9 and $12.3 \%$, respectively. Sodium elements come in $4^{\text {th }}$ position with $6.1,4.5$ and $6.0 \%$ followed by aluminium elements at 5.4, 3.3 and $6.7 \%$, respectively at spectrum 1,2 and 3 . In the category of the most noticeable elements, calcium comes in the last position with 5.1, 3.6 and 2.8\% at spectrum 1, 2 and 3, respectively. Other chemical elements such as magnesium $(\mathrm{Mg})$, iron (Fe), and potassium $(\mathrm{K})$ are found with lower percentage rate.

It has been reported that geopolymers made from fly ash or metakaolin, with an addition of excessive alkali ions, such as $\mathrm{Na}$, can result in these ions not being efficiently utilized as the network modifier [63]. Instead, these ions reside mainly in the pore solution in the form of carbonates when exposed to the atmosphere [63]. These carbonates further precipitate as salts thereby adversely effecting the geopolymer's mechanical properties [64, 65]. The same effect seen on the strength and stiffness of the material with a high $\mathrm{Na} / \mathrm{Si}$ ratio has also been reported in fly ash and red mud-based geopolymer by Zhang et al. [66]. On the other hand, despite the leaching crystals, the samples were almost hardened and did not affect the compressive strength at 7 days

curing. However, it is noteworthy to mention that the hardness of the samples activated with sodium hydroxide solution is not as high as those activated with both sodium hydroxide and sodium silicate solutions. Therefore, these experimental tests suggest that concentrated $\mathrm{NaOH}$ solution only does not seem to be a good activating agent for loess geopolymer.

\subsubsection{Porosity analysis}

Mercury Intrusion Porosimetry (MIP) was used to obtain the pore size distribution of the loess GPM. The Micromeritics Instrument Corporation AutoPore IV 9500 Version 2.00 was used to show the pore structure of the GPM with 70\% loess of Mix 1 and Mix 2 after 28 days of curing. 
The results showing both cumulative and incremental intrusion against pore size length are depicted in Fig. 9 (a-b). Manifestly, the porosity of the mortars at full mercury intrusion vary from $3.99^{-31} \mathrm{~mL} / \mathrm{g}$ to about $2.77^{-1} \mathrm{~mL} / \mathrm{g}$, and the size of the pores varied over the range $10-100000 \mathrm{~nm}$ (Fig. 9a). It is pertinent to note that the pores diameter in the hydrated paste varies from nano-to micro-scale. The critical pore radius representing the recurring pore radius in the interconnected pore structure is determinable from the peak value in the cumulative intrusion curve [67].

In this study, based on the incremental intrusion curves in Fig. 9(b), the 28 days critical pore radius for Mix 1 and Mix 2 are almost the same. According to other studies, thermal activation during the curing process usually affects the growth of porosity in geopolymers. Generally at $60^{\circ} \mathrm{C}$, geopolymer materials show lower sizes of pores but a higher total pore volume as opposed to being cured at room temperature. In this work, the geopolymer samples were heat-cured for one day at $70^{\circ} \mathrm{C}$ and then kept at room temperature until they were tested. This factor can equally affect the material's porosity. Other researchers claimed that most of the porosity observed in geopolymer materials cured at a high degree was of small pores, whereas those at room temperature were mostly of larger ones [68-70]. This can be attributed to two factors. The first factor is the temperature effect on the degree of reaction. The geopolymer samples subjected to room temperature present a lower degree of reaction, which may cause a higher porosity. The second factor relates to the synthesis process, which showed that at certain stages trapped water expulsion during contraction of the gel was observed. This may have subsequently caused pore development. Therefore, based on the strength-porosity results, it is evident that compressive strength is inversely proportional to porosity, that is, an increase of porosity renders a decrease in compressive strength. Also, the use of both $\mathrm{NaOH}$ and $\mathrm{Na}_{2} \mathrm{SiO}_{3}$ can reduce the pores in loess based-geopolymer matrices, thus enhance its compressive strength.

\subsubsection{SEM analysis}

The crushed fraction of geopolymer mortars were collected for SEM analyses and the results are displayed in Fig. 10. The SEM images of Fig. 10(a-b) are the GPM activated exclusively with $\mathrm{NaOH}$. They also present a structure similar to a non-reactive system having freely connected micro-particles and micro-cracks. The interspace amid particles is empty and the disconnected matrices are higher in the mixture. The $100 \%$ and $70 \%$ loess mortars with $\mathrm{NaOH}$ were less compact as they were mostly loose matrix. The SEM of loess mortars with $\mathrm{NaOH}+\mathrm{Na}_{2} \mathrm{SiO}_{3}$ appeared to 
be denser compared to those activated with only $\mathrm{NaOH}$. The SEM images of Fig. 10(c-d) show less volume of unreacted particles and denser matrices compared to those of the mix activated using $\mathrm{NaOH}$ only. The results agree with previous research findings on the use of sodium hydroxide in combination with sodium silicate as far as acceleration of geopolymerization process is concerned [71, 72]. Moreover, the increase in GGBS content, as seen, equally increases the reaction, thus have a direct effect on the microstructure. The optimum 28 day strength of 27.26 $\mathrm{MPa}$ was attained by $70 \%$ loess $+30 \%$ GGBS mix with $\mathrm{NaOH}+\mathrm{Na}_{2} \mathrm{SiO}_{3}$ solution. For this mixture, the matrix appeared compact and homogenous. As noted, the reaction of GGBS led to additional $\mathrm{CSH}$ and alkali solutions, which, consequently modified the microstructure of the mortar.

\subsection{Nanomechanical analysis}

\subsubsection{Shrinkage mechanisms of geopolymer coatings}

Geopolymer appears as a compatible material with concrete substrates [73]. The main matter to be considered when applying geopolymer coatings to concrete at ambient temperature is shrinkage. This can be defined as the volume reduction caused by the loss of water, generally due to drying. However, in the case of geopolymer, shrinkage may occur when water is consumed during geopolymerization [74]. There are two principal mechanisms of dry shrinkage when geopolymer coating is used to repair a concrete substrate. The first is the water loss through evaporation generated by a low environmental humidity and the second is due to the diffusion of water into the dried and porous concrete substrate from the moist geopolymer.

\subsubsection{Nanoindentation measurements}

The nanoindentation measurements were done as per the procedure described in Section 3.6. For each indent, a trapezoid load function was applied to a maximum of $5000 \mu \mathrm{N}$, with a linear loading time of $10 \mathrm{~s}$, a holding time of $5 \mathrm{~s}$ and a linear unloading time of 10s. Since the applied load $P$ and the depth $h$ were recorded during the test (Fig.8), the indentation modulus $M$ and hardness $H$ can be derived as below:

$$
M=\frac{\sqrt{\pi}}{2} \frac{S}{\sqrt{A_{C}}}
$$


$\mathrm{H}=\frac{P_{\max }}{A_{c}}$

Eq. (7)

Where $S$ represents the initially measured slope of the unloading segment of the $P-h$ curve (Fig. 11) and $A_{c}$ is the projected contact area of the sample surface. The relation between the indentation modulus and the sample modulus can be described by the following equation:

$$
\frac{1}{M}=\frac{1-v^{2}}{E}+\frac{1-v_{i}^{2}}{E_{i}}
$$

in which, $E$ and $v$ are elastic modulus and Poisson's ratio of tested samples. For a Berkovich tip used in this test, $E_{i}=1141 \mathrm{GPa}$ and $v i=0.07$. The Poisson's ratio $v$ here is assumed to be $0.2[75]$.

\subsubsection{Nanoindentation analysis}

Fig. 12 shows the 2D contour maps of Mix 1 and Mix 2 activated at ambient temperature with $\mathrm{NaOH}$ and the combination of $\mathrm{NaOH}$ and $\mathrm{Na}_{2} \mathrm{SiO}_{3}$, respectively. The brighter colors in the 2D contour maps represent higher indent modulus or hardness, while the darker colors mean lower indent modulus or hardness. The axes of the contour maps are the original coordinates for each indent recorded by the TriboIndentor.

The characteristics of the samples are present in Fig 13. The distribution of the indent modulus clearly depicts the region of loess GPM, the concrete and the Interfacial Transition Zones (ITZs). In the region between -85.48 and -85.40 of the $\mathrm{X}$-axis, a relatively constant indent modulus is shown, indicating a value of $\sim 80 \mu \mathrm{m}$ ITZ between mortar and concrete. This is inconsistent with the result shown in Fig. 12(d), Fig. 13(c) and Fig. 13(d). The indent modulus of the ITZ of Mix 2 is lower than the bulk indent modulus of the mortar and the concrete mostly due to the so-called "wall" effect $[76,77]$, resulting in a higher porosity close to the surface of the old concrete. This led to a buildup of water and fine particles within the zone.

The ITZ from concrete to mortar in Mix 1 cannot be clearly identified in Mix 2 (Fig. 12ac) but distinct differences of the indent modulus and hardness between the mortar and the concrete are observed in the contour maps. The darkest area in the contour maps of Mix 1 represent 0 indent modulus or hardness, resulting from the discontinuous load-displacement plots classified as invalid indents by Constantinides and Ulm [78], which were caused by poor surface preparation of the 
samples. The heterogeneity of the concrete is evident both in the indent modulus and the hardness contour maps, showing great variances in colors corresponding to the nano-mechanical properties of the concrete.

In contrast to the concrete, both mortar mixtures present an approximate homogeneous appearance. The loess geopolymer mortar activated with only $\mathrm{NaOH}$ has lower average hardness of up to $0.3 \mathrm{GPa}$ with an indent modulus of about $3 \mathrm{GPa}$ (Fig. 12a-b). As for the loess geopolymer mortar activated with $\mathrm{NaOH}$ and $\mathrm{Na}_{2} \mathrm{SiO}_{3}$, a similar degree of heterogeneity was observed in Fig. 12(c-d) with a deviation in the concrete region as showed in Fig. 13(c-d). It is important to notice that the bulk indent modulus and hardness of mortar Mix 2 are higher than those of Mix 1 with an average of $20 \mathrm{GPa}$ and $0.8 \mathrm{GPa}$, respectively. This is due to the addition of sodium silicate in the mixture that enhances the properties of the loess geopolymer mortar.

\section{Conclusion}

This study focused on the synthesis of high volume loess with partial addition of ground granulated blast slag. It also reserached on effective ways of using loess in the building industry. Accordingly, several experiments were undertaken to examine the properties and suitability of the material activated by different alkali solutions, in order to establish its applicability for protective coating. The main findings from the results of the experiments and the analysis of the data are summarized below:

- Loess can be effectively synthesized with both alkali liquids and $\mathrm{Na}_{2} \mathrm{SiO}_{3}$ is the main activator affecting the viscosity and shear stress of developed loess GPMs, and also helps the coating surface to be less rough.

- The relatively high compressive strengths of up to 3.99, 10.63 MPa and 17.25, 27.26 MPa can be obtained for $100 \%$ loess and $70 \%$ loess, repectively, with only $\mathrm{NaOH}$ solution and the mixture of $\mathrm{NaOH}+\mathrm{Na}_{2} \mathrm{SiO}_{3}$ solution.

- The addition of $\mathrm{Na}_{2} \mathrm{SiO}_{3}$ in the mixture can enhance the synthesis of GPMs and improve its compressive strength. Moreover, the partial addition of GGBS into loess contributes to the formation of extra $\mathrm{CSH}$, which helps the material's structure to be more compacted with less porosity.

- The activation of the mixture with only $\mathrm{NaOH}$ results in low resistance and leaching of white crystals that are mainly alkaline salt. These ions reside mainly in the pore 
solution in the form of carbonates when exposed to the atmosphere, adversely effecting the material's properties

- Based on the nanoindentation results, the bulk indent modulus and hardness of the mixture activated with $\mathrm{NaOH}$ and $\mathrm{Na}_{2} \mathrm{SiO}_{3}$ solutions are higher than that of the mixture activated with only $\mathrm{NaOH}$.

According to the results presented in this paper, there are promising ways to apply geopolymer to concrete subtrate as barrier coating. An additional evaluation of the material, including its bond strength, and long-term durability, is required to gain more insight of the new material. Furthermore, research relating to the influence of the concentration of activators, particularly, under ambient temperature curing is also required to attain higher mechanical, durability and microstructural properties for wider applications of the sustainable loess geopolymer.

\section{Acknowledgements}

The authors gratefully acknowledge the support of National Nature Science Foundation of China (Grant No: 51978414 and No: 51708363) and from the Royal Society, UK (IECINSFCI181449).

\section{Data Availability Statement}

This proposed article contains all data, models, and code created or employed during this study.

\section{Reference}

[1] M.S. Imbabi, C. Carrigan, S. McKenna, Trends and developments in green cement and concrete technology, International Journal of Sustainable Built Environment 1(2) (December 2012) 194216.

[2] P. Ghadir, N. Ranjbar, Clayey soil stabilization using geopolymer and Portland cement, Construction and Building Materials 188 (2018) 361-371.

[3] J.B.M. Dassekpo, X.X. Zha, J.P. Zhan, Synthesis reaction and compressive strength behavior of loess-fly ash based geopolymers for the development of sustainable green materials, Constr. Build. Mater. 141 (2017) 491-500.

[4] G. Medina, I.F.S. del Bosque, M. Frias, M.I.S. de Rojas, C. Medina, Durability of new recycled granite quarry dust-bearing cements, Construction and Building Materials 187 (2018) 414-425.

[5] J.B.M. Dassekpo, J.Q. Ning, X.X. Zha, Potential solidification/stabilization of clay-waste using green geopolymer remediation technologies, Process Saf. Environ. Protect. 117 (2018) 684-693.

[6] M.F. Zawrah, R.A. Gado, N. Feltin, S. Ducourtieux, L. Devoille, Recycling and utilization assessment of waste fired clay bricks (Grog) with granulated blast-furnace slag for geopolymer production, Process Safety and Environmental Protection 103 (2016) 237-251. 
[7] J.B.M. Dassekpo, X.X. Zha, J.P. Zhan, Compressive strength performance of geopolymer paste derived from Completely Decomposed Granite (CDG) and partial fly ash replacement, Constr. Build. Mater. 138 (2017) 195-203.

[8] I. Cretescu, M. Harja, C. Teodosiu, D.N. Isopescu, M.F. Chok, B.M. Sluser, M.A.M. Salleh, Synthesis and characterisation of a binder cement replacement based on alkali activation of fly ash waste, Process Safety and Environmental Protection 119 (2018) 23-35.

[9] L. Bergamonti, R. Taurino, L. Cattani, D. Ferretti, F. Bondioli, Lightweight hybrid organicinorganic geopolymers obtained using polyurethane waste, Construction and Building Materials 185 (2018) 285-292.

[10] W.S. Brito, A. Silva, R. Santa, K. Svensson, J.A.D. Souza, H. Pollmann, H.G. Riella, An Assessment of Reuse of Light Ash from Bayer Process Fluidized Bed Boilers in Geopolymer Synthesis at Ambient Temperature, Advances in Materials Science and Engineering (2018) 6.

[11] S. Samal, N.P. Thanh, B. Marvalova, I. Petrikova, Thermal Characterization of MetakaolinBased Geopolymer, Jom 69(12) (2017) 2480-2484.

[12] W.J. Long, X.W. Tan, B.X. Xiao, N.X. Han, F. Xing, Effective use of ground waste expanded perlite as green supplementary cementitious material in eco-friendly alkali activated slag composites, Journal of Cleaner Production 213 (2019) 406-414.

[13] N.N. Shao, Z. Liu, J.J. Fan, Y. Zhou, D.M. Wang, Phase evolution of fly ash calcium constituent at early alkali activation reaction age, Materials Letters 174 (2016) 175-179.

[14] D.S. Yu Jin, The unusual solidification process of alkali activated slag and its relationship with the glass structure of the slag, Cem. Concr. Res. 121 (2019) 1-10 (2019).

[15] D. Khale, R. Chaudhary, Mechanism of geopolymerization and factors influencing its development: a review, Journal of Materials Science 42(3) (2007) 729-746.

[16] G.F. Huseien, J. Mirza, M. Ismail, M.W. Hussin, Influence of different curing temperatures and alkali activators on properties of GBFS geopolymer mortars containing fly ash and palm-oil fuel ash, Construction and Building Materials 125 (2016) 1229-1240.

[17] D. Hardjito, S.E. Wallah, D.M.J. Sumajouw, B.V. Rangan, Factors influencing the compressive strength of fly ash based geopolymer concrete, Civ. Eng. Dimension 6 (2004) 88-93. [18] K. Bashir, Fly ash-based geopolymer concrete, Int. J. Mech. Civ. Eng. (2014) 19-23.

[19] J.B.M. Dassekpo, X.X. Zha, J.P. Zhan, J.Q. Ning, The effects of the sequential addition of synthesis parameters on the performance of alkali activated fly ash mortar, Results Phys. 7 (2017) 1506-1512.

[20] M. Komljenovic, Z. Bascarevic, V. Bradic, Mechanical and microstructural properties of alkali-activated fly ash geopolymers, Journal of Hazardous Materials 181(1-3) (2010) 35-42.

[21] A. Palomo, M.W. Grutzeck, M.T. Blanco, Alkali-activated fly ashes - A cement for the future, Cement and Concrete Research 29(8) (1999) 1323-1329.

[22] J.G.S. van Jaarsveld, J.S.J. van Deventer, Effect of the alkali metal activator on the properties of fly ash-based geopolymers, Industrial \& Engineering Chemistry Research 38(10) (1999) 39323941.

[23] M. Steveson, K. Sagoe-Crentsil, Relationships between composition, structure and strength of inorganic polymers - Part 2 - Flyash-derived inorganic polymers, Journal of Materials Science 40(16) (2005) 4247-4259.

[24] K. Somna, C. Jaturapitakkul, P. Kajitvichyanukul, P. Chindaprasirt, NaOH-activated ground fly ash geopolymer cured at ambient temperature, Fuel 90(6) (2011) 2118-2124. 
[25] C.Y. Heah, H. Kamarudin, A.M.M. Al Bakri, M. Bnhussain, M. Luqman, I.K. Nizar, C.M. Ruzaidi, Y.M. Liew, Kaolin-based geopolymers with various $\mathrm{NaOH}$ concentrations, International Journal of Minerals Metallurgy and Materials 20(3) (2013) 313-322.

[26] D. Panias, I.P. Giannopoulou, T. Perraki, Effect of synthesis parameters on the mechanical properties of fly ash-based geopolymers, Colloids and Surfaces a-Physicochemical and Engineering Aspects 301(1-3) (2007) 246-254.

[27] F. Pacheco-Torgal, D. Moura, Y.N. Ding, S. Jalali, Composition, strength and workability of alkali-activated metakaolin based mortars, Construction and Building Materials 25(9) (2011) 3732-3745.

[28] P. Duxson, Provis, J.L., Lukey, G.C., van Deventer, J.S.J., The role of inorganic polymer technology in the development of 'green concrete', Cement and Concrete Research 37, 1590-1597 (2007).

[29] P.J. Zhang Z, Reid A, Wang H., Geopolymer foam concrete: an emerging material for sustainable construction, Constr Build Mater 2014; 56:113-27. (2014).

[30] W.R. McLellan BC, Lay J, Van Riessen A, Corder GD., Costs and carbon emissions for geopolymer pastes in comparison to ordinary portland cement., J Clean Prod 2011; 19:1080-90. (2011).

[31] Y.X. Zhang Z, Zhu H., Potential application of geopolymers as protection coatings for marine concrete: II. Microstructure and anticorrosion mechanism, Appl Clay Sci 2010; 49:7-12 (2010).

[32] L.S. Geissert DG, Frantz GC, Stephens JE., Splitting prism test method to evaluate concreteto-concrete bond strength, ACI Mater J 1999; 96:359-66 (1999).

[33] E.M. Momayez A, Ramezanianpour A, Rajaie H., Comparison of methods for evaluating bond strength between concrete substrate and repair materials, Cem Concr Res 2005; 35:748-57 (2005).

[34] M.P. L. Biondi, C. Vlachakis, Z. Wu, A. Hamilton and J. McAlorum, Ambient cured fly ash geopolymer coatings for concrete, Materials 2019, 12, 923 (2019).

[35] S.G. Hu, H.X. Wang, G.Z. Zhang, Q.J. Ding, Bonding and abrasion resistance of geopolymeric repair material made with steel slag, Cement \& Concrete Composites 30(3) (2008) 239-244.

[36] C.-G.J. Pacheco-Torgal F, Jalali S., Adhesion characterization of tungsten mine waste geopolymeric binder. Influence of OPC concrete substrate surface treatment, Constr Build Mater 2008; 22:154-61 (2008).

[37] H.S. Suksiripattanapong C, Chanprasert P, Sukmak P, Arulrajah A., Compressive strength development in fly ash geopolymer masonry units manufactured from water treatment sludge, Constr Build Mater 2015; 82:20-30 (2015).

[38] P.T. Songpiriyakij S, Pungpremtrakul P, Jaturapitakkul C., Anchorage of steel bars in concrete by geopolymer paste, Mater Des 2011; 32:3021-8.

[39] Y.R. Li, A review of shear and tensile strengths of the Malan Loess in China, Eng. Geol. 236 (2018) 4-10.

[40] S.C.Porter, Loess records, China, Encyclopedia of Quaternary Science (2007) 1456-1466.

[41] H.M. Roberts, D.R. Muhs, E.A.B. III, Loess records, North America, Encyclopedia of Quaternary Science (2007) 1456-1466.

[42] D.-D. Rousseau, E. Derbyshire, P. Antoine, C. Hatté, Loess Records, Europe, Encyclopedia of Quaternary Science (2007) 1440-1456.

[43] M.A. Zárate, Loess Records, South America, Encyclopedia of Quaternary Science (2007) 1466-1479. 
[44] X. D., Q., Qi, X., Fan, X., Dong, X., Li, S., Ju, Y., Study on early recognition of loess landslides based on field investigation, Int. J. Geohazards Environ. 2 (2), 32-52 (2016).

[45] R.D. C Shi, Early strength development and hydration of alkali-activated blast furnace slag/fly ash blends, Advances in Cement Research 11 (4), 189-196 (1999).

[46] A.B.Æ.H.H.Æ.C. Kaps, Alkali-activated metakaolin-slag blends-performance and structure in dependence of their composition, J Mater Sci 42:3024-3032 (2007).

[47] Z. Xiaoxiong, J.B.M. Dassekpo, Compression and characterization of alkali-activated loess, IOP Conference Series: Materials Science and Engineering 431 (2018) 092012 (8 pp.)-092012 (8 pp.).

[48] BaekJoong, K.-I. Kang, Characteristics of Natural Loess(Hwangtoh) Paste Subjected to Geopolymerization, Journal of the Korea Concrete Institute 23(1) (2011) 121-127.

[49] Z. Liu, C.S. Cai, F.Y. Liu, F.H. Fan, Feasibility Study of Loess Stabilization with Fly AshBased Geopolymer, J. Mater. Civ. Eng. 28(5) (2016) 8.

[50] L. Jia, Zhang, L., Guo, J., Yao, K., Lim, S. M., Li, B., \& Xu, H., Evaluation on Strength Properties of Lime-Slag Stabilized Loess as Pavement Base Material. , Sustainability, 11(15), 4099. (2019).

[51] W.F. Jean-Baptiste Mawulé Dassekpo, Manuel Monasterio, Lixin Miao, Zhijun Dong, Effect of alkali-activators on loess geopolymer: a potential waterproof repair material, Journal of Materials in Civil Engineering, DOI: 10.1061/(ASCE)MT.1943-5533.0003784 (2021).

[52] M.J. Huseien GF, Ismail M, Hussin MW., nfluence of different curing temperatures and alkali activators on properties of GBFS geopolymer mortars containing fly ash and palm-oil fuel ash., Constr Build Mater 2016; 125:1229-40. (2016).

[53] L.A. Al-Majidi MH, Cundy A, Meikle S., Development of geopolymer mortar under ambient temperature for in situ applications. , Constr Build Mater 2016; 120:198-211. (2016).

[54] K. Yao, Pan, Y., Jia, L., Yi, J. T., Hu, J., \& Wu, C. , Strength evaluation of marine clay stabilized by cementitious binder., Marine Georesources \& Geotechnology, 1-14. (2019).

[55] A. C39/C39M-16a, Standard Test Method for Compressive Strength of Cylindrical Concrete Specimens, ASTM International, West Conshohocken, PA (2016).

[56] BS EN 1504-3:2005 - Products and systems for the protection and repair of concrete structures. Definitions, requirements, quality control and evaluation of conformity. Structural and nonstructural repair, 2005.

[57] W.D. Liu Z, Sub-distributions of pore size: a new approach to correlate pore structure with permeability, Cement and Concrete Research 1995, 25(4): 769-778 (1995).

[58] C.B. M. Miller, M. Vandamme, F.-J. Ulm, Surface roughness criteria for cement paste nanoindentation, Cement and Concrete Research 38 (2008) 467-476 (2008).

[59] J.L. Provis, Duxson, P., van Deventer, J.S.J., Lukey, G.C.,, The role of mathematical modelling and gel chemistry in advancing geopolymer technology, Chemical Engineering Research and Design 83 (A7), 853-860 (2005).

[60] D.G. Panias, I.P.; Perraki, T., Effect of synthesis parameters on the mechanical properties of fly ash-based geopolymers, Colloids and Surfaces A: Physicochemical and Engineering Aspects 301, 246-254 (2007).

[61] J. Temuujin, R.P. Williams, A. van Riessen, Effect of mechanical activation of fly ash on the properties of geopolymer cured at ambient temperature, Journal of Materials Processing Technology 209(12-13) (2009) 5276-5280. 
[62] T. Phoo-Ngernkham, A. Maegawa, N. Mishima, S. Hatanaka, P. Chindaprasirt, Effects of sodium hydroxide and sodium silicate solutions on compressive and shear bond strengths of FAGBFS geopolymer, Construction and Building Materials 91 (2015) 1-8.

[63] Y. Fang, Structure and development of fly ash and red mud-based geopolymers, School of Engineering and Information Technology, University of New South Wales, Australian Defence Force Academy, 2013.

[64] P. Duxson, G.C. Lukey, F. Separovic, J.S.J. van Deventer, Effect of alkali cations on aluminum incorporation in geopolymeric gels, Industrial \& Engineering Chemistry Research 44(4) (2005) 832-839.

[65] W.K.W. Lee, J.S.J. van Deventer, The effects of inorganic salt contamination on the strength and durability of geopolymers, Colloids and Surfaces a-Physicochemical and Engineering Aspects 211(2-3) (2002) 115-126.

[66] G.P. Zhang, J.A. He, R.P. Gambrell, Synthesis, Characterization, and Mechanical Properties of Red Mud-Based Geopolymers, Transportation Research Record (2167) (2010) 1-9.

[67] M.B.-K. P. Pipilikaki, The assessment of porosity and pore size distribution of limestone Portland cement pastes, Constr. Build. Mater. Volume 23(5) (2009) Pages 1966-1970.

[68] D.S. Kong, J.G.; Sagoe-Crentsil, K., Comparative performance of geopolymers made with metakaolin and fly ash after exposure to elevated temperatures, Cem. Concr. Res. 37 [12] (2007) 1583-1589.

[69] H.-J.R. Kang, G-S.; Koh, G-T.; Kang, S-T.; Park, J-J. , Relationship between microscopic structures and compressive strength of alkali-activated fly ash mortar, Key Eng. Mat. (Advances in Fracture and Damage Mechanics IX) (2011) 452-453 / 737-740.

[70] J.S. Nemecek, V.; Kopecky, L.; Nemeckova, J. , Nanoindentation of alkali-activated fly ash, Transp. Res. Record. 2141 (Nanotechnology in Cement and Concrete 2010, Volume 1) (2010) 3640.

[71] C.R. Kaze, J.N.Y. Djobo, A. Nana, H.K. Tchakoute, E. Kamseu, U.C. Melo, C. Leonelli, H. Rahier, Effect of silicate modulus on the setting, mechanical strength and microstructure of ironrich aluminosilicate (laterite) based-geopolymer cured at room temperature, Ceramics International 44(17) (2018) 21442-21450.

[72] T. Phoo-ngernkham, Hanjitsuwan, S., Damrongwiriyanupap, N., \& Chindaprasirt, P., Effect of sodium hydroxide and sodium silicate solutions on strengths of alkali activated high calcium fly ash containing Portland cement., KSCE Journal of Civil Engineering, 21(6), 2202-2210. (2016). [73] G.F. Huseien, J. Mirza, M. Ismail, S.K. Ghoshal, A.A. Hussein, Geopolymer mortars as sustainable repair material: A comprehensive review, Renew. Sust. Energ. Rev. 80 (2017) 54-74. [74] P.J. Lura, O.M.; van Breugel, K., Autogenous shrinkage in high-performance cement paste: An evaluation of basic mechanisms, Cem. Concr. Res. 2003, 33, 223-232 (2003).

[75] M. Vandamme, The nanogranular origin of concrete creep : a nanoindentation investigation of microstructure and fundamental properties of calcium-silicate-hydrates, Dept. of Civil and Environmental Engineering., Massachusetts Institute of Technology, 2008.

[76] A.K.C. K.L. Scrivener, P. Laugesen, The Interfacial Transition Zone (ITZ) Between Cement Paste and Aggregate in Concrete, Interface Sci. 12 (2004) 411-421 (2004).

[77] N.R. J. Spangenberg, J.H. Hattel, H. Stang, J. Skocek, M.R. Geiker, Flow induced particle migration in fresh concrete: Theoretical frame, numerical simulations and experimental results on model fluids, Cem. Concr. Res. 42 (2012) 633-641 (2012).

[78] F.-J.U. G. Constantinides, The nanogranular nature of C-S-H, J. Mech. Phys. Solids 55 (2007) 64-90 (2007). 
Table

Table 1 Chemical composition of loess and GGBS

\begin{tabular}{lll}
\hline Elements as oxides & Loess Wt $(\%)$ & GGBS Wt $(\%)$ \\
\hline $\mathrm{SiO}_{2}$ & 60.07 & 19.87 \\
$\mathrm{Al}_{2} \mathrm{O}_{3}$ & 25.09 & 5.92 \\
$\mathrm{SO}_{3}$ & 0.72 & 4.14 \\
$\mathrm{Fe}_{2} \mathrm{O}_{3}$ & 7.57 & 3.63 \\
$\mathrm{CaO}$ & 1.58 & 62.75 \\
$\mathrm{TiO}_{2}$ & 0.77 & 0.30 \\
$\mathrm{MnO}$ & 0.18 & 0.82 \\
$\mathrm{MgO}$ & 1.42 & 2.23 \\
$\mathrm{~K}_{2} \mathrm{O}$ & 2.56 & 0.73 \\
$\mathrm{Na}_{2} \mathrm{O}$ & 0.24 & 0.92 \\
\hline
\end{tabular}




\section{Figures}

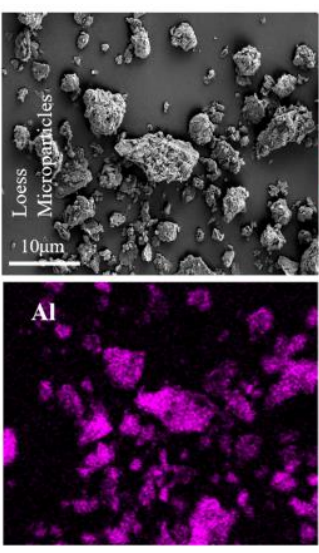

(a) Loess
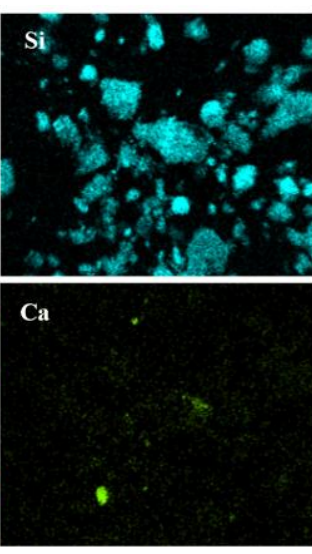

Fig. 1 SEM micrographs and oxides distribution mapping
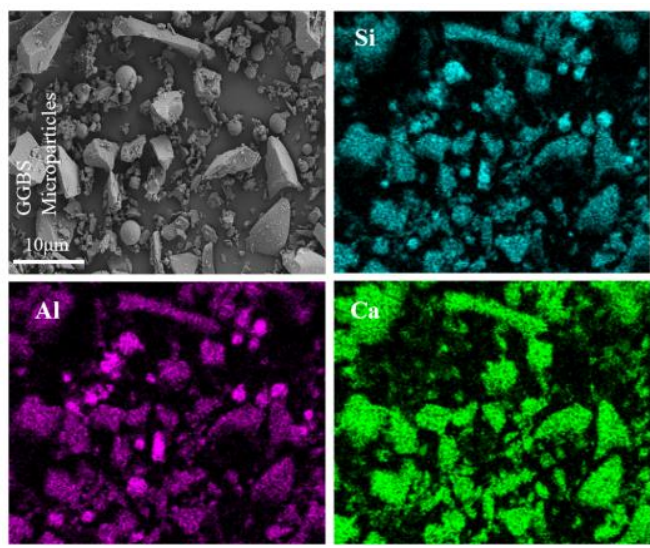

(b) GGBS
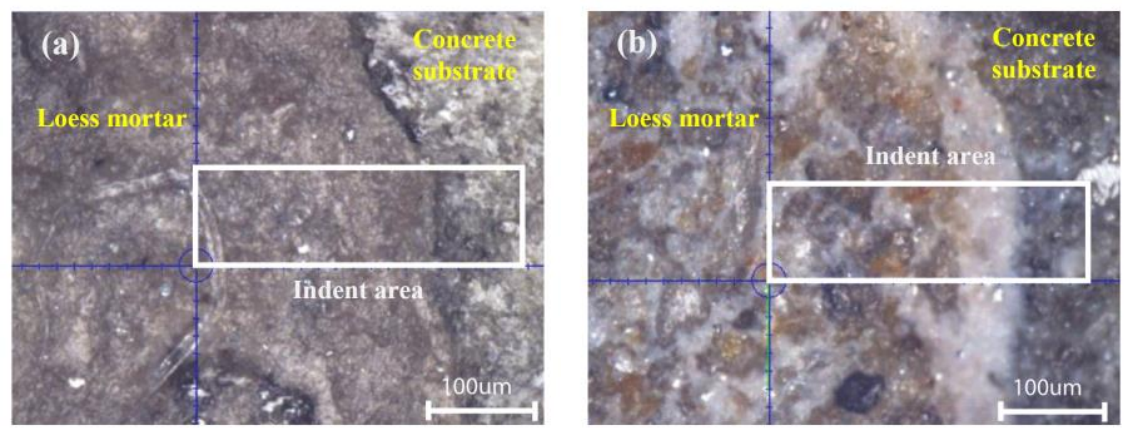

Fig. 2 Indent area: (a) Mix 1; (b) Mix 2 

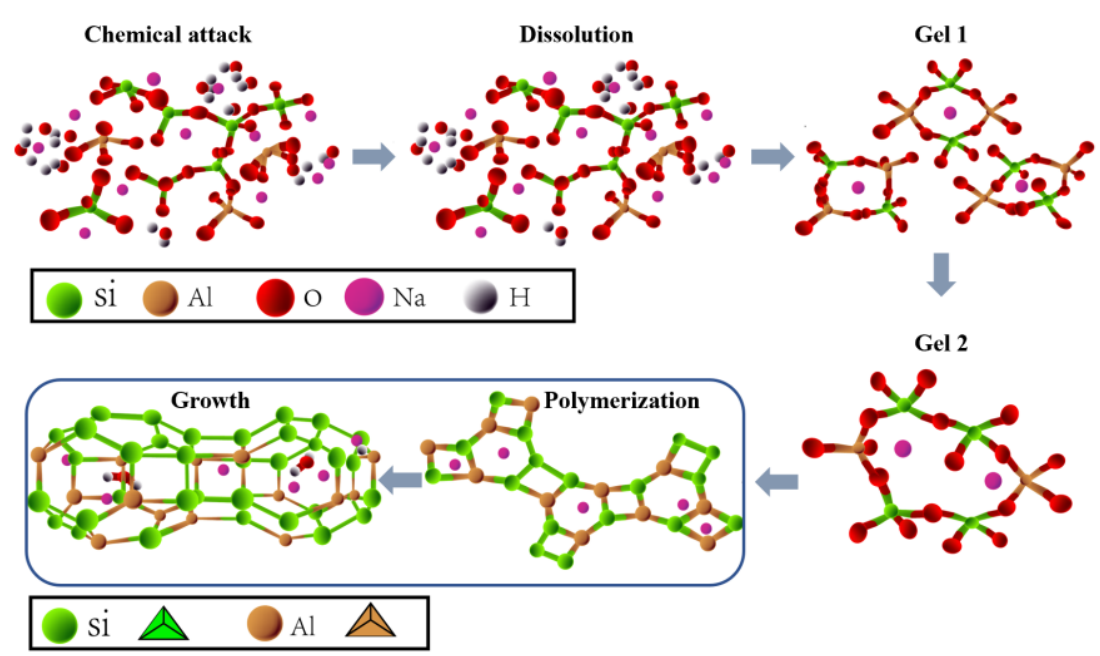

Fig. 3 Schematic showing the geopolymer reactions process
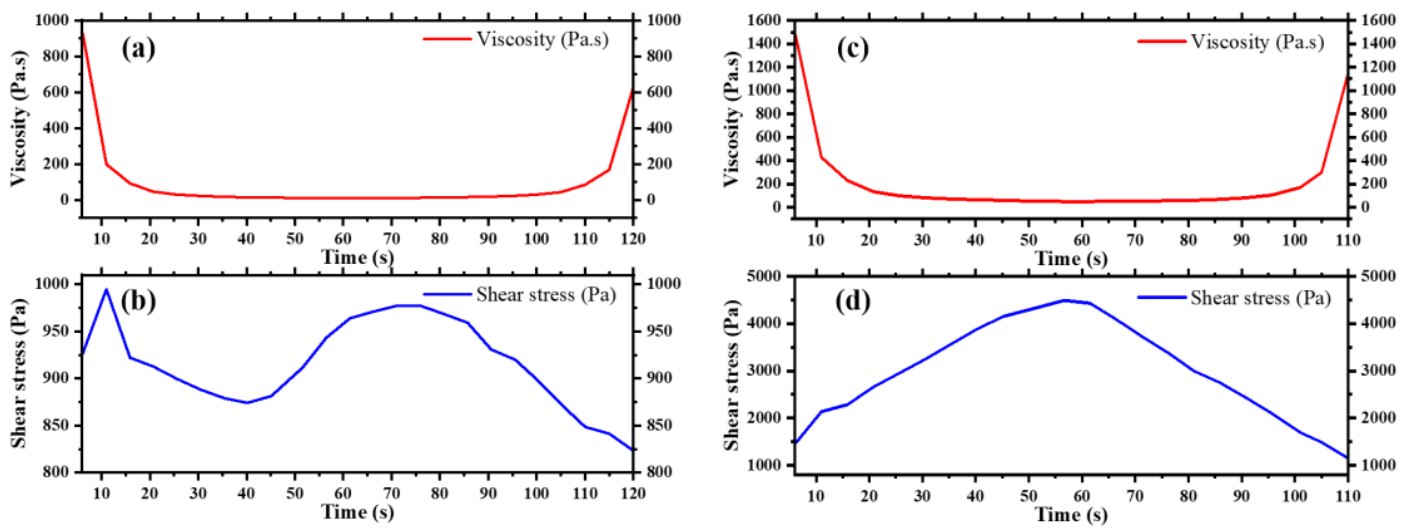

Fig. 4 Viscosity of GPMs: (a) Mix 1 viscosity; (b) Mix 1 shear stress;

(c) Mix 2 viscosity; (d) Mix 2 shear stress 


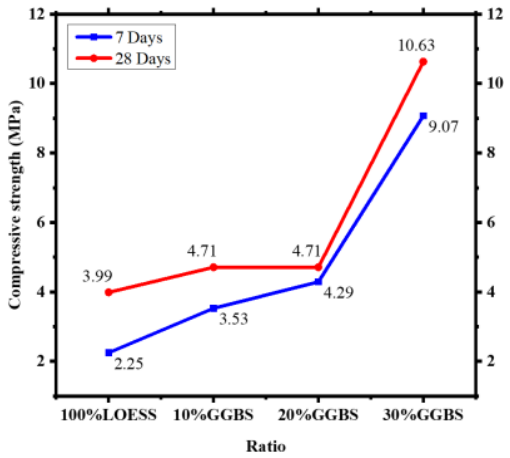

(a) Mixture with $\mathrm{NaOH}$

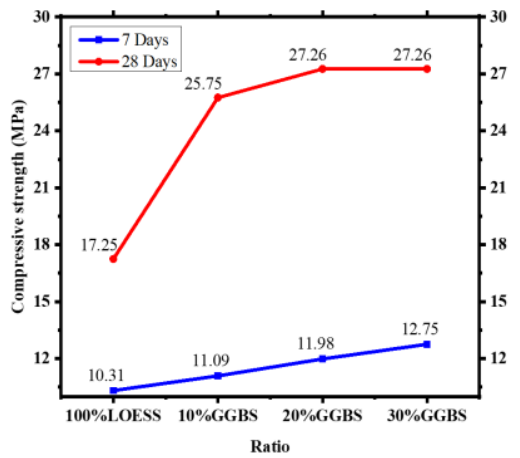

(a) Mixture with $\mathrm{NaOH}+\mathrm{Na}_{2} \mathrm{SiO}_{3}$
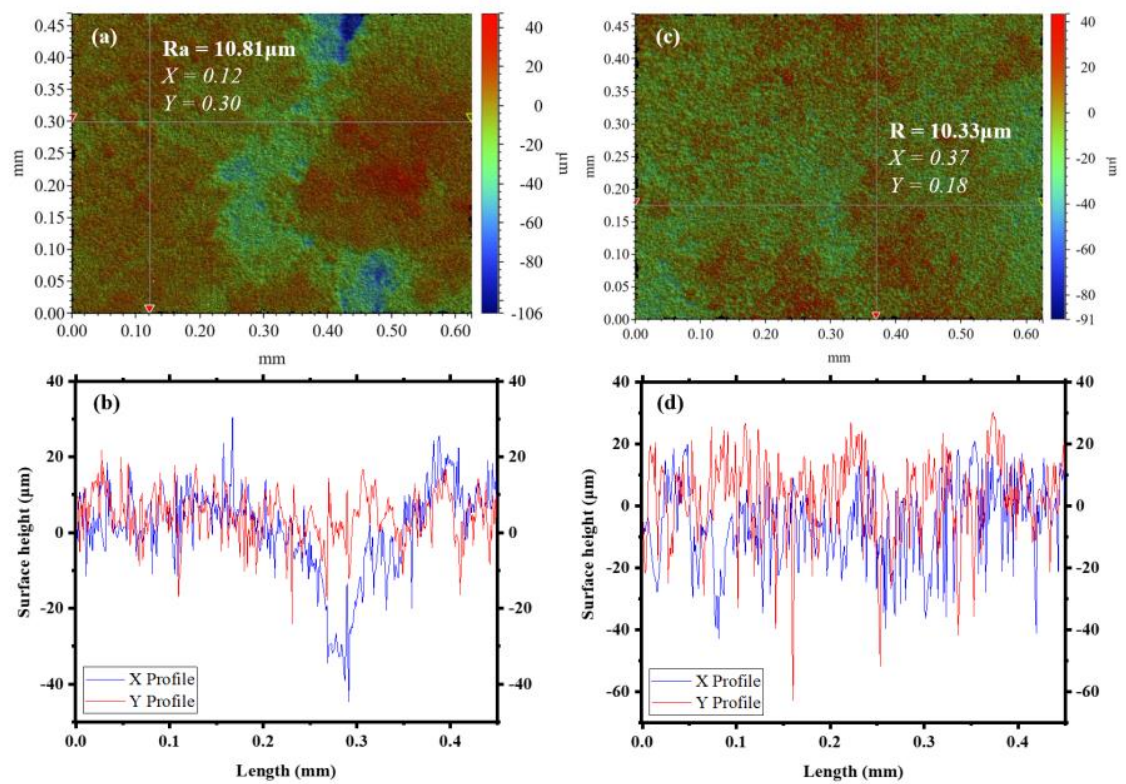

Fig. 6 Surfaces roughness: (a) Mix 1 coating; (b) Mix 1 surface profile; (c) Mix 2 coating; (d) Mix 2 surface profile 


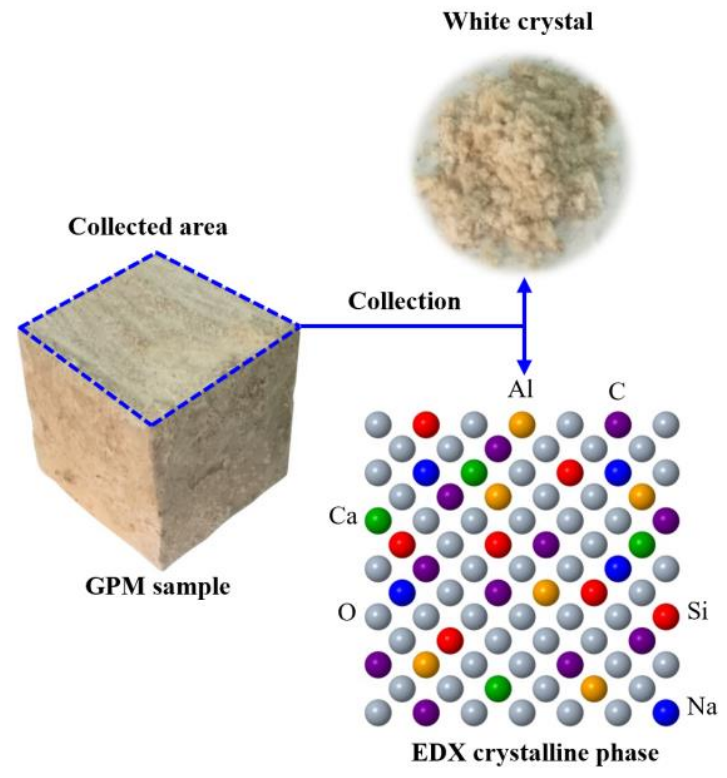

Fig. 7 Collection and analysis of the white crystal
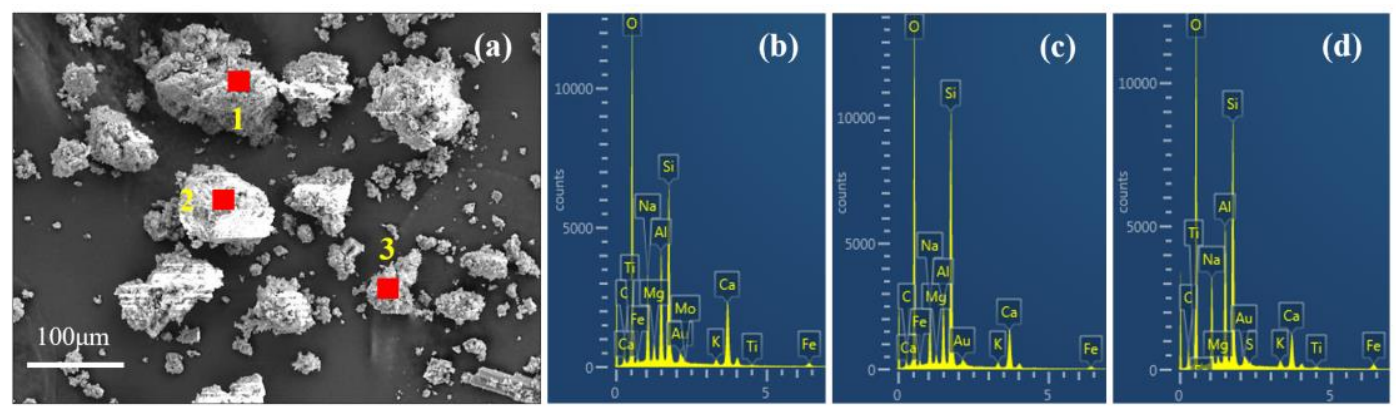

Fig. 8 Microanalysis of white crystal:

(a) EDX morphology; (b) Spectrum 1; (c) Spectrum 2; (d) Spectrum 3
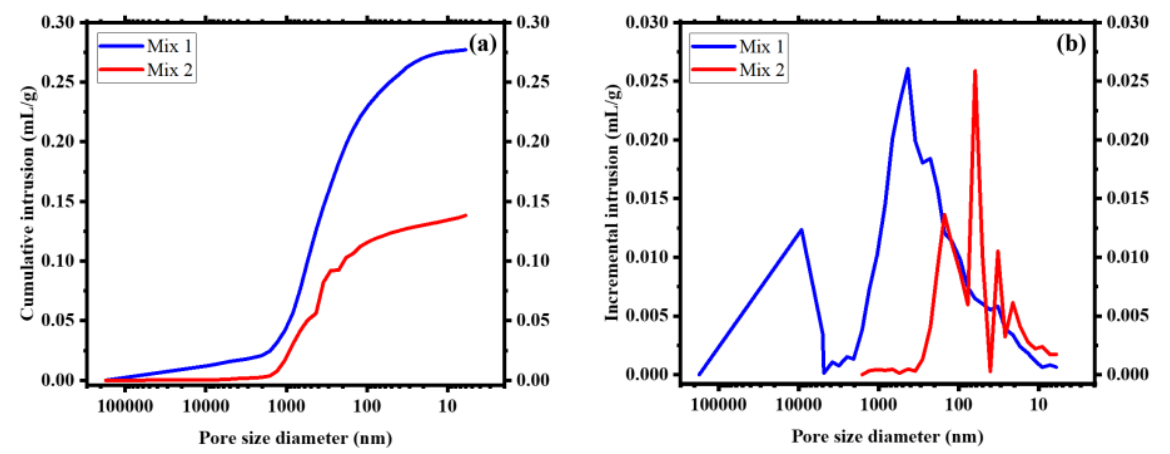

Fig. 9 Porosity analysis of Mix 1 and Mix 2:

(a) Cumulative intrusion; (b) Incremental intrusion 

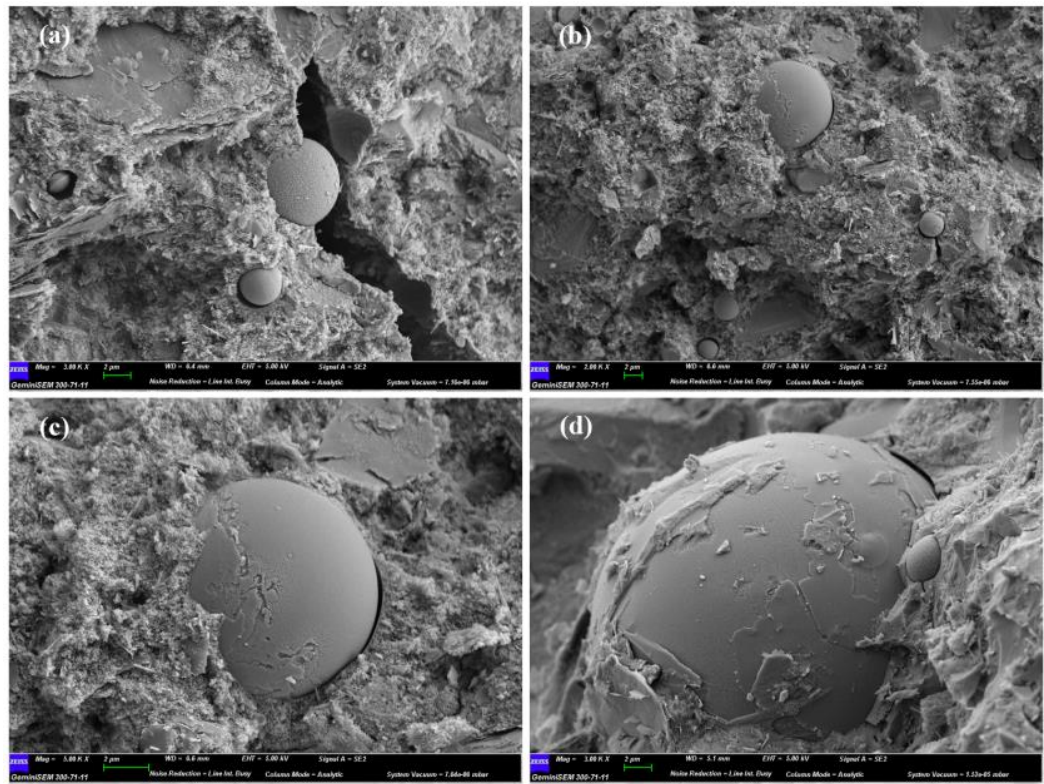

Fig. 10 SEM micrographs: (a) Mix 1 with $100 \%$ loess; (b) Mix 1 with $70 \%$ loess and 30\% GGBS; (c) Mix 2 with 100\% loess; (d) Mix 2 with 70\% loess and $30 \%$ GGBS

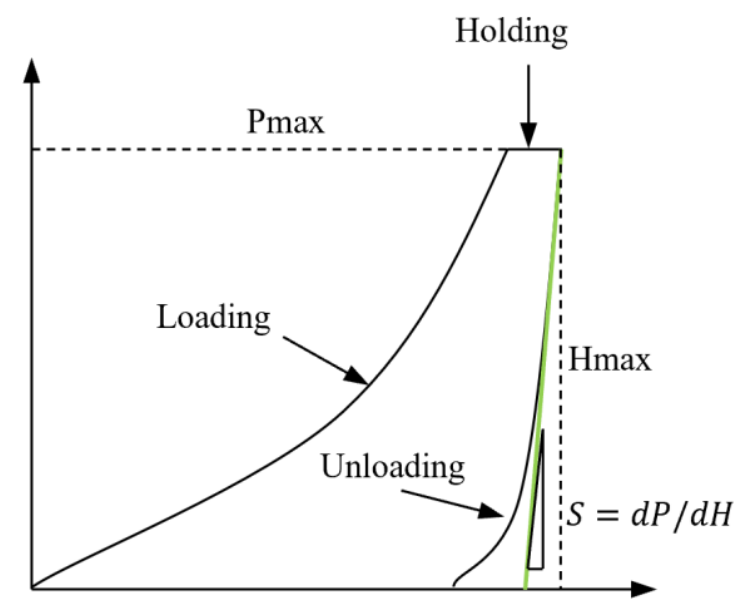

Fig. 11 Schematic of load-displacement curve from nanoindentation 


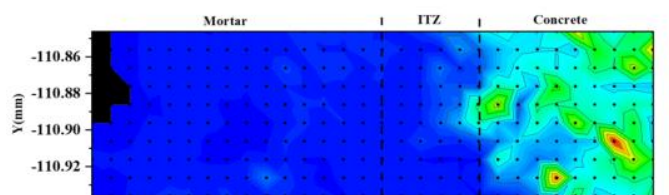

(a)

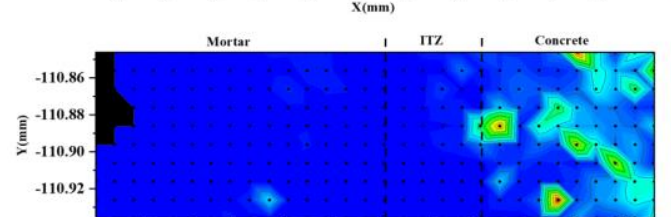

(b)
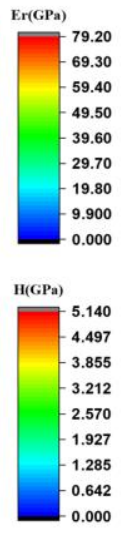

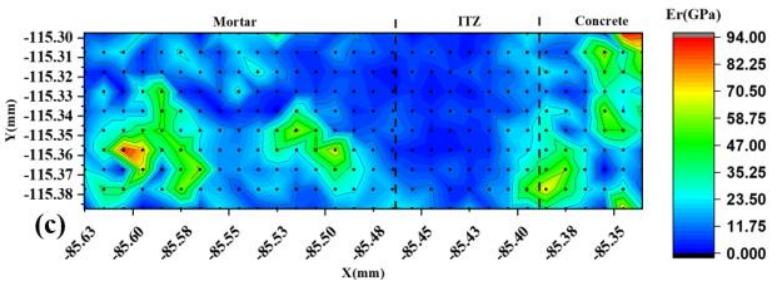

Mortar

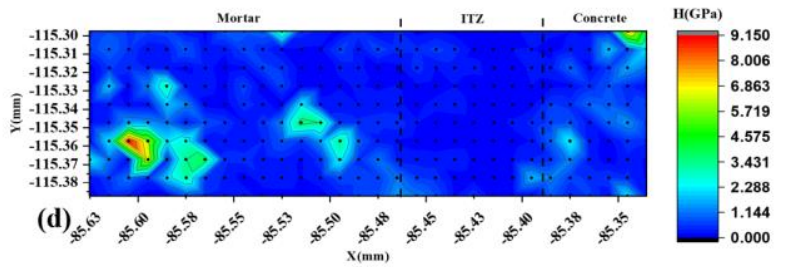

Fig. 12 Nanomechanical properties of loess GPM: (a) Indent modulus contour map in Mix 1; (b) Hardness contour map in Mix 1; (c) Indent modulus contour map in Mix 2; (d) Hardness contour map in Mix 2
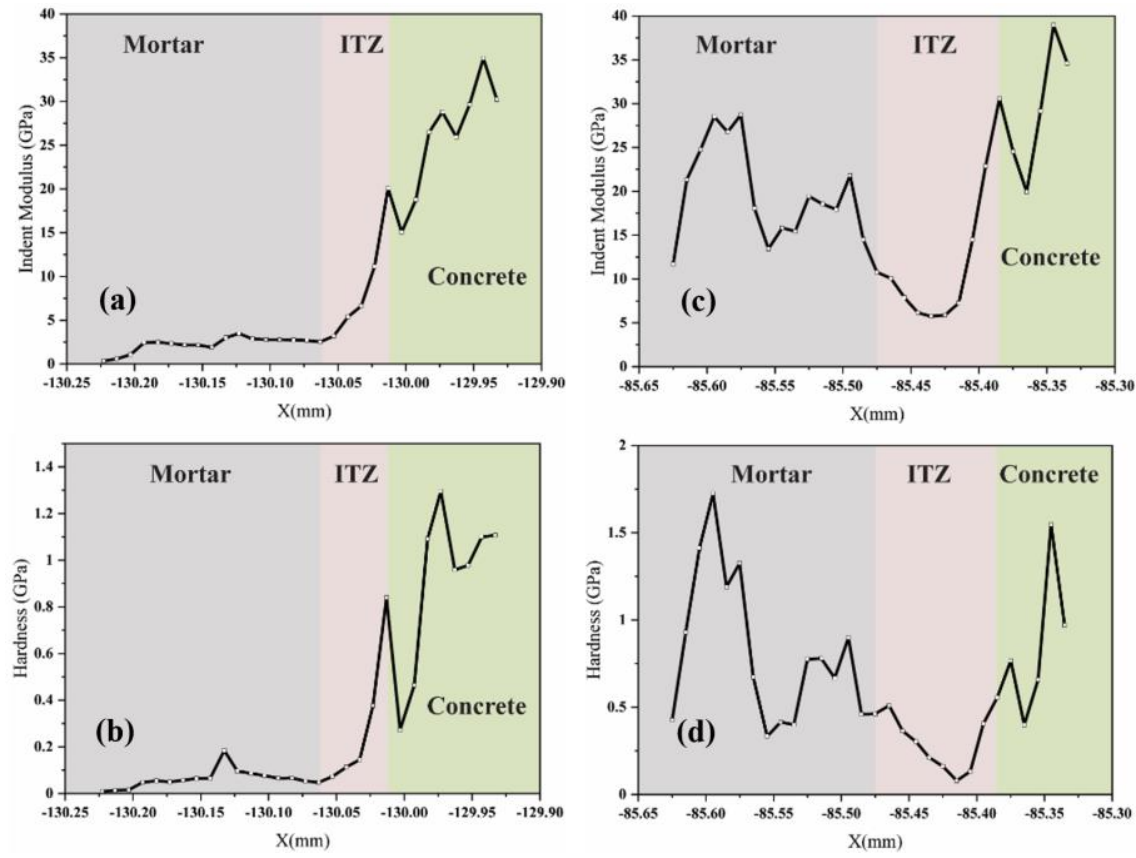

Fig. 13 ITZ Characterization in Mix 1 and Mix 2: (a) Indent modulus distribution in Mix 1; (b) Hardness distribution in Mix 1; (c) Indent modulus distribution in Mix 2; (d) Hardness distribution in Mix 2 